\title{
Seguridad de género en adolescentes escolares rurales. Un análisis del Programa Escuelas Seguras en México ${ }^{1}$
}

\author{
Gender Security in Adolescents of Rural Schools: An \\ Analysis of the Safe School Program in Mexico
}

\section{Segurança de gênero em adolescentes das escolares rurais. Uma análise do Programa Escolas Seguras, no México}

\author{
Julio U. Morales-López \\ Investigador-Docente CONACYT-CIESAS Pacífico Sur \\ Centro de Investigaciones y Estudios Superiores en Antropología Social \\ México \\ Recibido: 15/9/ 2017 Aprobado: 15/11/2017
}

Resumen

La seguridad de género es un concepto trabajado por la autora Úrsula Oswald (2013), el cual resulta adecuado para analizar valores de desventajas que refuerzan ciertos procesos de riesgo, miedo y afrentas contra la dignidad que de forma específica actúan sobre determinados tipos de personas. En este artículo se evidencian factores de vulnerabilidad que atentan contra un concepto integral de seguridad, sustentabilidad y desarrollo. A partir de la investigación etnográfica se discute sobre las condiciones ideales en que las escuelas del nivel básico

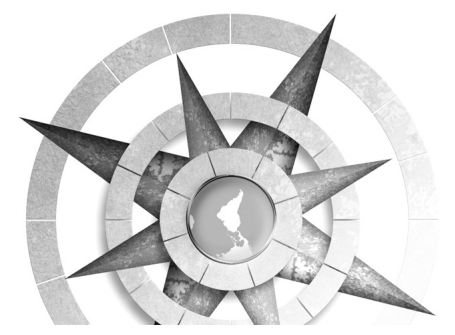

DOI: https://doi.org/10.15359/tdna.34-63.4 en México deberían ejercer sus actividades, garantizando en todo momento el desarrollo integral de niñas, niños y adolescentes (NNA) estudiantes, sin ninguna prerrogativa. Se propone una reflexión sobre el Programa Nacional Escuela Segura (PES) desarrollado por el gobierno mexicano, su aplicación institucional y comunitaria. Se busca advertir si contempla una perspectiva de género que en la práctica contribuya a cimentar la seguridad de género, la resolución de conflictos y la educación para la paz. Se enfatiza en las transferencias de la violencia comunitaria hacia los contextos escolares, sobre todo, constituyendo de esta forma, la escuela como espacio masculinizado.

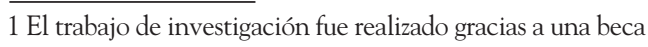
posdoctoral de la Universidad de Guanajuato Campus Celaya-Salvatierra y el Consejo Nacional de Ciencia y Tecnología CONACYT de México, a través del proyecto: "Género, violencia y marginación en escuelas de nivel básico y media superior en el Sur del estado de Guanajuato"; cuya responsable técnica fue la Dra. Rocío Rosas Vargas de la Universidad de Guanajuato UG. 
Palabras clave: Género, infancia, violencia, riesgos, seguridad, América Latina, derechos humanos.

\section{Abstract}

Gender security is a concept the author Úrsula Oswald (2013) has been working on, which is appropriate to analyze values of disadvantages that reinforce certain processes of risk, fear and affronts against the dignity that specifically act on certain types of people. This article describes vulnerability factors that can weaken a comprehensive concept of security, sustainability and development. From the ethnographic research approach, the article discusses the ideal conditions in which primary and secondary schools in Mexico should exercise their activities, ensuring at all times the integral development of children and adolescents, without any prerogative. It proposes a reflection on the Programa Nacional Escuela Segura (PES-National Safe School Program, developed by the Mexican government), and its institutional and community implementation. The aim is to determine if the program contemplates a gender perspective that, in practice, contributes to strengthening gender security, conflict resolution, and peace education. Emphasis is placed on the transfer of community violence toward school contexts, especially turning the school, in this way, into a masculinized space.

Keywords: Gender, childhoods, violence, risks, security, Latin America, human rights.

\section{Resumo}

A segurança de gênero é um conceito trabalhado pela autora Úrsula Oswald (2013) o qual resulta adequado para analisar valores de desvantagens que reforçam determinados processos de risco, medo e ameaças contra a dignidade que, de forma específica, atuam sobre determinados tipos de pessoas. Nesse artigo ficam evidentes os fatores de vulnerabilidade que atentam contra um conceito integral de segurança, sustentabilidade e desenvolvimento. A partir da investigação etnográfica, discute-se sobre as condições ideais nas quais as escolas mexicanas do nível básico deveriam exercer suas atividades, garantindo em todo momento o desenvolvimento integral das crianças e adolescentes estudantes (NNA), sem nenhuma prerrogativa. Propõe-se uma reflexão sobre o Programa Nacional Escola Segura (PES) desenvolvido pelo governo mexicano, sua aplicação institucional e comunitária. Procura fazer perceptível a existência de uma perspectiva de gênero que, na prática, contribua a cimentar a segurança de gênero, a resolução de conflitos e a educação para a paz. Enfatiza-se as transferências da violência comunitária para os contextos escoares, constituindo desta forma, a escola como espaço masculinizado.

Palavras-chave: Gênero, infâncias, violência, riscos, segurança, América Latina, direitos humanos.

64 Seguridad de género en adolescentes escolares rurales. Un análisis del Programa Escuelas Seguras en México Julio U. Morales-López 


\section{Introducción}

Los contextos rurales son espacios socioculturales que manifiestan fuertes arraigos a los roles de género tradicionales, estos han sido transmitidos de forma intergeneracional y fueron afianzados en las reiteraciones mismas. Sin embargo, las actuales generaciones poseen mayores grados de escolaridad y el contexto escolar es un espacio formativo que podría construir relaciones más armoniosas entre los géneros para reflexionar así una conceptualización amplia de educar a la niñez y la juventud.

No obstante, para comprender lo que "en la escuela ocurre" se debe enfatizar en las relaciones sociales adyacentes. Es claro que la escuela no puede seguirse estudiando únicamente como espacio acotado, aislado del espacio comunitario. De tal manera, los profesores, directivos y estudiantes confluyen en el espacio escolar, pero confrontan sus mundos culturales y psicológicos en espacios que perfilan relaciones conflictivas y violentas. Otro argumento es que estas relaciones violentas se hacen aún más complejas cuando incorporamos mayores elementos de discriminación, como roles tradicionales de género y desigualdades hacia todo lo que constituye lo femenino, en consecuencia, desde una perspectiva antropológica las escuelas pueden resultar verdaderos campos de batalla físicos, verbales y simbólicos entre los intereses de todas las pluralidades que ahí confluyen.

La pregunta fundamental para reflexionar es ¿si existen en los ámbitos escolares argumentos suficientes para que la población estudiantil pueda advertir la inseguridad de género?, para de esta forma delimitar su acción y sus consecuencias como manifestaciones violentas y conflictivas que son una constante en la vida de las y los estudiantes. En el sentido anterior, nos preguntamos si los directivos, profesores y administrativos están capacitados para desarrollar una sensibilidad que les permita comprender los elementos de inseguridad de género. A esto último se suma la preocupación de pensar que las sociedades tienden a presentar mayores elementos de violencia visible que en décadas anteriores derivada de la actual política social y de seguridad que ha implementado el gobierno federal desde el sexenio del expresidente Felipe Calderón (2006-2012), la cual ha tenido complejas repercusiones en todos los estados y municipios de la República, ocasionando una proliferación de zonas conflictivas y violentas en regiones antes rurales-tradicionales. 
De igual forma se suma la reflexión sobre el papel que el Estado mexicano debe desempeñar como responsable y garante de la integridad física, psicológica y social de las comunidades y sus sujetos. Desde una metodología etnográfica se realiza un análisis del Programa Nacional Escuela Segura (PES) de la Subsecretaría de Educación Básica de la Secretaría de Educación Pública (SEP), ya que como cita dicho Programa se advierte la necesidad de la "seguridad al resguardo de la integridad física, afectiva y social en la escuela, así como en el entorno comunitario que rodea a las escuelas".

El PES es una ambiciosa propuesta que sin duda perfila una preocupación sobre la seguridad del alumnado. Sin embargo, desde este análisis, no contempla un modelo de seguridad escolar ni del entorno comunitario con una perspectiva integral y prospectiva, ya que, primero, carece de un análisis hacia la inseguridad de género, y en segundo término, advierte características de seguridad solo desde prerrogativas estrictamente masculinas.

\section{Seguridad y seguridad de género}

Desde la teoría social, en la obra clásica El Leviatán de Thomas Hobbes, la seguridad es el resultado a cambio de la libertad, ya que al aceptar libremente la obediencia al soberano el ser humano se pone bajo su tutela, cediendo el poder y la vigilancia de la seguridad busca librarse de la muerte. La seguridad hace referencia a la condición de estar libre de sufrir opresión, daño físico o muerte a través de actos violentos cometidos por otros. Para Recasens:

el hombre político que hoy somos y que nos hemos dejado ser, es cada vez más débil de ciudadanía y menos protegido por la sociedad civil, entra más fácilmente al drama de los mass media: servidumbre voluntaria a cambio de ser salvado de lo que nos expone al miedo. Es lo que Franz Neumann llama la estructuración social mediante el binomio perverso política y angustia... el resultado final es que un pueblo será capaz de cederle sus derechos constitucionales al Estado a cambio de la seguridad que le promete (2005: 39).

Podemos decir que el miedo y la inseguridad son pares que co-sustentan en una espiral de progresiva violencia. Así, esta relación produce una pérdida de calidad de vida de los habitantes al limitar sus desplazamientos (Recasens, 2005).

Por su parte, una idea sugerida de Zigmunt Bauman (2000) nos explica que es imposible concebirse como

66 Seguridad de género en adolescentes escolares rurales. Un análisis del Programa Escuelas Seguras en México Julio U. Morales-López 
seres humanos sin seguridad y libertad; pero no podemos tener ambas a la vez en cantidades que consideremos plenamente satisfactorias. Según este autor, en el discurso de la modernidad, la seguridad y libertad existirán ligadas a los conceptos de clase y ciudadanía de los cuales no se desprenderían hasta la fecha.

Desde el año 1994 el Informe sobre el Desarrollo Humano del Programa de las Naciones Unidas para el Desarrollo (PNUD) se centró en el concepto de seguridad humana, cuya definición contemplaba la seguridad económica, alimenticia, de salud, medioambientales, comunitarias y políticas como un concepto diferente a los trabajados anteriormente cuyo enfoque de amenaza a la seguridad estaba basado en ámbitos militares, de soberanía, integridad territorial y políticas de Estados. Por lo tanto, en dicho sentido, el individuo debe estar antes que el Estado como referente de la seguridad, por lo que las amenazas contra el individuo y su seguridad pueden ser: el hambre, la enfermedad, la polución, la violencia, las desigualdades y discriminaciones (Mack, 2005).

En la mención que se hizo en la ONU sobre el informe Nosotros los pueblos: la función de las Naciones Unidas en el siglo XXI (2000) se expone la necesidad de aplicar mayores criterios de seguridad cercanos al ser humano y no solo la de la ausencia de conflictos, entre ellos los armados; en este sentido, evidenciaba el peligro que provoca el agotamiento de recursos, en especial, el agua potable y la degradación ambiental como elementos constituyentes de la seguridad; así como los abusos a los derechos humanos, los desplazamientos y refugiados, el virus del VHI-SIDA. También se hace énfasis en las mujeres como sujetos vulnerables a la violencia y la explotación sexual. El informe subraya que en caso de no "proteger a los más vulnerables todas las iniciativas de seguridad y de paz serán a la vez frágiles e ilusorias" (2000: 42). Asimismo, la ONU señala la necesidad de prestar una atención más sistemática al cumplimiento de los compromisos sobre las mujeres, la paz y la seguridad, particularmente, con el fin de reforzar la intervención de las mujeres en la prevención, solución de conflictos y la consolidación de la paz.

Alejandra Massolo comenta que cada tipo de violencia tiene sus victimarios y víctimas. La inseguridad pública y la inseguridad privada afectan de una u otra forma la vida cotidiana y casi impiden imaginar un ambiente seguro y protegido. Los agravios de violencia y la impunidad

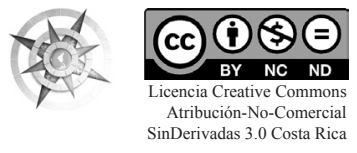


motivan el reclamo de "seguridad en movilización de protestas y otras manifestaciones de malestar" (2005: 644). Esta autora advierte que el término de seguridad es por sí solo problemático, por ejemplo, en la actualidad se habla más de "seguridad ciudadana" que de "seguridad pública", en tanto que en la década de 1980 el debate estaba en la "seguridad nacional". Seguridad ciudadana se refiere a las recuperaciones institucionales de las democracias latinoamericanas, su defensa de los derechos ciudadanos contra excesos de fuerzas estatales, la criminalidad (2005: 645).

Lo anterior, nos facilita argumentar que el concepto de seguridad ha sido construido históricamente como un debate en torno a lo que el Estado deberá proveer y lo que los individuos exigen al Estado, así también, los ámbitos en que objetiva y subjetivamente se puede definir la seguridad, por un lado, lo relacionado con el miedo y el sentimiento de inseguridad provocado más que la parte psicológica, por otro lado, su construcción social como elemento integrador de discursividades públicas, que normarán toda la vida social como ya se ha visto antes con Recasens.

En consecuencia, es necesario reflexionar que dentro de esta desprotección y exclusión de seguridad que debería garantizar el Estado, los sentimientos y percepciones de inseguridad tienen un marcado sesgo de género aunado a otros sectores discriminados. Para Zeitlin y Mpoumou "la seguridad humana centrada en las personas no implica necesariamente un enfoque de seguridad humana sensible al género" (2004: 3). Más aún:

Es esencial comprender el concepto de seguridad humana desde una perspectiva de género para mejorar, también, la seguridad de las mujeres desde una visión integral y holística. Esto no significa que las metas y objetivos de igualdad de género deban incorporarse al enfoque de seguridad humana, sino que se diferencian en las cuestiones centrales de la seguridad de la mujer y la del hombre (2004: 4).

Una importante autora sobre las seguridades es Úrsula Oswald, quien ha defendido tres tipos de seguridades correlativas que deben existir como "ambientes ecosociales". Ella enfatiza en la seguridad ambiental, donde se hace referencia a los ecosistemas, los valores de riesgo que constituyen la sustentabilidad y las amenazas hacia la naturaleza y la humanidad, también la seguridad humana cuya referencia es la humanidad y los individuos, y los valores de riesgo

68 Seguridad de género en adolescentes escolares rurales. Un análisis del Programa Escuelas Seguras en México Julio U. Morales-López 
son la supervivencia, la calidad de vida, y la integridad cultural. En concordancia con lo anterior, la autora expone el concepto de seguridad de género:

cuyo objeto de referencia son las mujeres, los niños, los indígenas, los ancianos y en general las minorías, que identifican sus valores de riesgo en las relaciones de género, la equidad, la identidad y las relaciones sociales siendo las fuentes de amenaza el patriarcado, expresado en las instituciones totalitarias, violentas y autoritarias y se basan en la intolerancia (Centro Tepoztlán AC, 2010: 2).

Oswald advierte cuatro fundamentos para la seguridad humana: 1) la ausencia de amenazas, 2) la ausencia de miedo, 3) el vivir con dignidad, 4) la ausencia de riesgos naturales. La seguridad de género parte de un concepto amplio de la categoría que se refiere a las relaciones y al estatus social otorgados a mujeres, indígenas, minorías vulnerables y hombres en franca desventaja por razones de género, que provoca discriminación y exclusión, ante esto, los valores de riesgo son la equidad y la identidad como fuentes de amenaza al orden patriarcal. En este sentido, la seguridad de género -reitera la autora- "deberá reflejarse en el bienestar, en mejor salud, alimentación y seguridad pública, así como la educación, la tolerancia ante la diversidad cultural en el entorno biodiverso"; así para Oswald la seguridad humana, la seguridad de género y la seguridad ambiental (HUGE, por sus siglas en inglés) deben producir procesos sustentables que procuren el desarrollo, equidad y sustentabilidad (2010: 3).

En otro documento, Oswald señala que la seguridad de género es un concepto en evolución desde las ciencias sociales y los estudios de género, donde se hace una crítica a las inequitativas relaciones verticales de poder entre los sexos basadas en un sistema de división social, laboral, económico, político y cultural; donde el género masculino ha dominado al género femenino. Para deconstruir el modelo dominante y proponer un concepto de seguridad de género es necesario liberarse de los postulados liberales positivistas androgénicos situados en una visión liberal del mundo occidental por medio de: 1) el feminismo epistemológico, 2) el feminismo empírico, 3) el posmodernismo feminista, $y$ 4) el feminismo del punto de vista (Oswald, 2013: 229).

Por su parte, la autora Betty Reardon fue una de las primeras que relacionó la cultura de guerra, el autoritarismo,

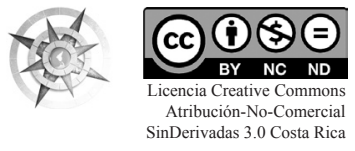


la violencia en el control y distribución del poder del hombre hacia las carencias y subordinación que las mujeres viven. Esta autora sugiere que "las profundas raíces de la violencia están arraigadas en relaciones violentas de género por miles de años" (Reardon, 1996, citada por Oswald, 2013: 230). Explica que el nacimiento de la violencia y su florecimiento como sistema es causado desde los argumentos psicológicos que estructuran el sexismo como una guerra sistémica. Lo anterior ha propiciado la separación entre los sexos originando las estructuras de violencia y opresión, asociando lo masculino con elementos de autoritarismo y control, mientras lo femenino lo asocia con la carencia de poder. Esta guerra sistémica ha sido constituida por toda la historia como un modelo basado en el patriarcado, formando nuestro orden social en autoritarismos principales, asumiendo relaciones inequitativas y valoraciones desiguales como fuerzas coercitivas. Lo anterior -según Reardon- formaría instituciones que dominarían todo el pensamiento, primero en Occidente; luego a las minorías, los pensamientos de los países industrializados, la educación, las relaciones entre las elites, los objetivos comunes, el mantenimiento del orden, control y dominio, todo descansa sobre una guerra sistémica, que involucra la intimidación, la violencia y coerción basadas en la fuerza, para aumentar las capacidades productivas, donde el patriarcado ejerce el control del poder, mientras las mujeres son subordinadas y viven carencias (Reardon, 1996, traducción propia).

Para la autora el concepto de guerra sistémica revela subconceptos interiores que nos permiten comprender argumentos asociados a nuestra discusión de seguridad; por ejemplo: militarismo, guerra legal, sanción, institucionalidad, fuerzas armadas organizadas, aplicación de la autoridad para el control social, objetivos públicos, protección de los intereses, etc.; todos los anteriores pueden ser usados para obtener las condiciones deseadas; de esta forma, la "seguridad" del Estado depende de la habilidad para la guerra.

El patriarcado ha tenido un papel central en la victoria de las elites masculinas en esta guerra (con sus pequeñas excepciones) de esta forma, haciendo la guerra, creando el derecho, depurando la religión y el pensamiento divino; así, todo conocimiento, ciencia y tecnologías han sido cerrados a las mujeres, utilizando como se ha dicho las fuerzas instrumentales del Estado, entre ellas, la militarización, cuya función es resolver los problemas y

70 Seguridad de género en adolescentes escolares rurales. Un análisis del Programa Escuelas Seguras en México Julio U. Morales-López

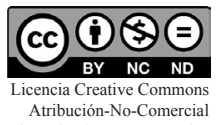


conflictos básicamente de orígenes políticos y económicos, utilizando el patriarcado como un modo de gobernanza (Reardon, 1996: 13-15, traducción propia).

En contraste, para Oswald hay tres fases de estudio de seguridad de género:

\section{1) El ecofeminismo.}

Profundizó en la diferencia entre género y sexualidad, y estableció una analogía entre explotación de las mujeres y la explotación de la naturaleza. De esta forma, el control de la naturaleza y el control del cuerpo de la mujer responden a las mismas dinámicas patriarcales dominantes, autoritarias, violentas y destructoras.

2) El estudio de las Representaciones Sociales (RS).

Vistas como sistema de valores, ideas y prácticas que cumplen una función dual: a) establecen un marco de orden a partir del cual los sujetos se orientan en el mundo social y material donde habitan, y b) permiten la comunicación entre los miembros de una comunidad a partir de un código compartido donde se nombran y clasifican objetos y procesos. De esta forma, la identidad y las RS se convierten en un valor de riesgo, cuando la seguridad de género se ve amenazada por los intereses patriarcales que no actúan individual ni subjetivamente.

\section{3) Los movimientos sociales.}

Son la tercera fase histórica de la seguridad de género como procesos de confluencia de diversos movimientos sociales aunados con las reflexiones sobre las inequidades hacia las mujeres derivadas de sistemas patriarcales dominantes, observando en las luchas de los oprimidos determinados valores constantes que reiteran procesos de dominación; evidenciando una relación de cuestionamientos contra los patrones tradicionales, ya que la oposición es algo que comparten todos los oprimidos, entre ellas las mujeres con todas sus múltiples identidades y formas de ser, lo anterior, bajo el énfasis de derrotar las diversas hegemonías (Oswald, 2013).

Entonces, la seguridad de género es un concepto que, diferenciado del de la seguridad humana, advierte una génesis histórica en momentos en que la especie humana perfiló y depuró el control masculino, institucionalizando los pensamientos y actuaciones de todo cuanto constituye el mundo de las ideas, de los aspectos materiales y el de las utopías. Desde lo anterior se colige que la seguridad de género va más allá de

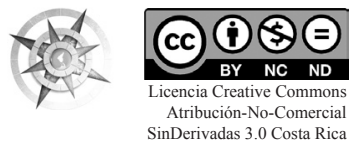


la suma protección y respeto de los derechos humanos de las mujeres, es además, un reclamo epistemológico y deconstructivo donde en sus inicios estamos obligados a concebir otro tipo de relaciones humanas desprovistas de violencias, inequidades y desigualdades.

\section{El Programa Escuelas Seguras en el marco de la inseguridad y violencia en México ${ }^{2}$}

En México la cotidianidad de la violencia impuesta por el crimen organizado y por pequeñas células delictivas ha desencadenado, también, la cotidianidad de sistemas violentos y represores que el Estado-nación ejecuta con el fin de contrarrestar el efecto violento en zonas donde la mala gobernabilidad y la corrupción política ya habían creado un crisol de problemáticas sociales.

Mientras, por otro lado, como una respuesta a la situación de extrema violencia e inseguridad que vive el país y sus repercusiones en los contextos escolares, el gobierno federal mexicano a través de la Secretaría

2 La República Mexicana está políticamente conformada por treinta y un estados y un Distrito Federal (hoy llamado Ciudad de México), unidos todos por un pacto federal. Para fines de este estudio Guanajuato se referencia como un estado, a diferencia de otros países donde se les llama provincias, comunidades autónomas, distritos, etc. de Educación Pública (SEP) ha lanzado el Programa Escuelas Seguras (PES). Por contextos escolares, entiéndanse todos los tipos de espacios escolares, itinerarios y espacios cercanos donde estudian, se reúnen, distraen, se transportan o recrean las y los estudiantes en relación con el motivo escolar, entiéndanse como espacios institucionales, públicos, vías o sistemas de transporte y comunicación.

El PES inicia sus funciones durante el sexenio del expresidente Felipe Calderón en julio de 2007. El Programa Nacional Escuela Segura forma parte desde julio de dicho año de la Estrategia Nacional de Seguridad "Limpiemos México", la cual establece vínculos de colaboración con diferentes instituciones, de forma prioritaria con la Secretaría de Seguridad Pública y su Programa "Comunidades Seguras", la Secretaría de Salud con el Programa Nacional "Salud solo sin drogas", la Secretaría de Desarrollo Social con el Programa "Recuperación". Si bien es en 2007 cuando se definen sus ámbitos de acción y creación, la última modificación se llevó a cabo con sus Reglas de Operación el 25 de febrero de 2013 con la publicación en el Diario Oficial de la Federación (DOF), donde se cita:

\footnotetext{
72 Seguridad de género en adolescentes escolares rurales. Un análisis del Programa Escuelas Seguras en México Julio U. Morales-López
}
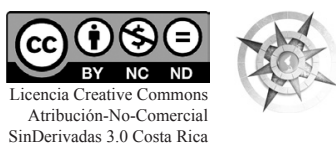
El Programa Escuela Segura (PES) es una iniciativa de la SEP que se orienta al fortalecimiento de la educación básica y se enmarca en lo establecido por los artículos $3^{\circ}$. de la Constitución Política de los Estados Unidos Mexicanos, 77 de la Ley Federal de Presupuesto y Responsabilidad Hacendaria; 176 de su Reglamento; 29 y anexo 24 del Presupuesto de Egresos de la Federación para el Ejercicio Fiscal 2013.

Por su parte, por "escuela segura" entiéndase:

Aquella que posee el potencial para reconocer los problemas que ponen en riesgo las condiciones de seguridad necesarias para el desarrollo de su función. Posee la capacidad de plantear una estrategia acorde a las necesidades de seguridad reconocidas por sus integrantes y de convocar e involucrarlos para asumir compromisos con las acciones que en colectivo se definan. Prevaleciendo un ambiente escolar democrático con diálogo y la toma de decisiones de manera participativa, en un marco de equidad y respeto, en torno a las medidas que previenen de situaciones de riesgo y violencia (Subsecretaría de Educación Básica, sin fecha, página web, mensaje de la Coordinación).

Entre los objetivos generales de dicho programa se hace énfasis a la seguridad y convivencia democrática, "la participación responsable y el desarrollo de competencias encaminadas al auto cuidado, la autorregulación, el ejercicio responsable de la libertad, la participación social y la resolución no violenta de conflictos" (SEP).

\section{Estudio de caso: inseguridad de género en contextos escolares en Salvatierra Guanajuato}

Se realizó una investigación etnográfica en dos escuelas secundarias en el municipio de Salvatierra. Se entrevistó a estudiantes, profesores y directivos, en los meses de junio de 2013 a febrero de 2014. Las edades de las y de los estudiantes eran de los 11 hasta los 19 años. Se realizaron 26 entrevistas a profundidad, dos talleres con adolescentes hombres enfocados en conocer aspectos de masculinidades en relación con estereotipos de violencia y discriminación. También, en estos contextos escolares, la investigación incluyó charlas y anotaciones informales con docentes de primaria y preescolar, autoridades locales, gente del pueblo, observación participante de eventos sociales, etnografía en las colonias con énfasis en sus espacios de reunión como: jardines públicos, iglesias y centros de salud. 
El municipio de Salvatierra está ubicado al sur del Estado de Guanajuato casi colindando con el Estado de Michoacán. Presenta una fuerte relación con el sector agrícola, y sobre todo con la migración internacional y en menor caso con otros estados de México. En cuanto al porcentaje de educación la media estatal es de 7.73 años (basado en un rango de personas mayores de 15 años), sin embargo, Salvatierra está por debajo con 6.80 años. Otro aspecto igual de importante es la mayor exclusión que las mujeres presentan con el $6.72 \mathrm{de}$ participación a diferencia del tampoco nada favorable 6.90 masculino (Secretaría de Desarrollo Social y Humano, 2012). Lo anterior, suma dos aspectos fundamentales para comprender quiénes son las y los jóvenes de esta investigación, ya que un gran porcentaje se encuentra excluido de aspectos de educación que puedan mejorar sus condiciones de vida en el futuro.

La gran mayoría de los estudiantes se desempeñan en trabajo de tipo infantil y juvenil después de la escuela, ya sea en las labores agrícolas, servicios, o bien, en el trabajo en el hogar. Existe un grave problema de deserción escolar por efecto de la migración, motivado por el estereotipo del migrante exitoso. También por la migración, los jóvenes experimentan el abandono o descuido del hogar de uno o los dos padres. Resulta muy común encontrar jóvenes viviendo con los abuelos o hermanos mayores.

Las entrevistas a docentes marcaban un contexto escolar con muchos aspectos de inseguridad, ellos evidenciaban las drogas, las pandillas, el alcoholismo y los delincuentes como principales argumentos de inseguridad que podrían afectar la integridad de las y los estudiantes. Estos aspectos eran, en el discurso de los profesores, elementos inherentes a la vida social de las comunidades y colonias, estaban presentes en la cotidianidad y difícilmente podrían modificarse. Retomando lo anterior, en estas instituciones de nivel secundaria existe en operación el PES con especial esfuerzo entre los gobiernos municipales y comunitarios para salvaguardar el bienestar de los alumnos.

Las funciones desempeñadas por el PES estaban enfocadas en labores de vigilancia y patrullaje en los alrededores de las escuelas, con especial atención en vialidades y contextos educativos cuando se trataba de festivales, desfiles y otras actividades, así como también la aplicación del Programa Mochila Segura que busca detectar objetos peligrosos, armas y drogas entre los estudiantes.

74 Seguridad de género en adolescentes escolares rurales. Un análisis del Programa Escuelas Seguras en México Julio U. Morales-López

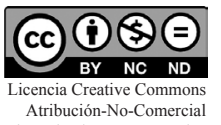


Según las entrevistas, la inseguridad para las autoridades escolares y docentes es textualmente concebida como un aspecto de violencia visible y violencia directa, aunque en el marco legal el PES contempla además crear entornos con armonía a la "integridad física, psicológica y social sobre la base del respeto a su dignidad", "fomentar la equidad, la inclusión, la resolución de conflictos desde vías democráticas e incluyentes". Sin embargo, cuando en la investigación procedemos del ámbito discursivo hacia la observación participante y la entrevista a los estudiantes, salen a flote elementos que contradicen estos preceptos, ya que la inseguridad tiende a ser interpretada por las autoridades y los docentes desde un punto de vista personal, sobre lo que ellos creen que es inseguro y no lo que la construcción integral de seguridad puede perfilar. La inseguridad de la que hablan los docentes y directivos se enfoca en atacar los aspectos mínimos de seguridad vista como la oportunidad de que los alumnos salgan de sus casas y lleguen a la escuela sin percances ni daños de ningún tipo, así como el viaje de retorno; incluso esta fue la explicación que hacen los directivos como sus responsabilidades: "lograr que el alumno llegue a la escuela y al salir de esta llegue a su casa sin percances es responsabilidad mía" -citaba un directivo-. Esta visión de seguridad compleja es comprensible, pues existe en un ámbito de seguridad personal y patrimonial, sin embargo, cuando se cuestionó a los alumnos sobre la violencia e inseguridad existen muchas prerrogativas que ponen en entredicho la integridad psicológica y social expuesta en el documento del PES.

Ahora me gustaría enfocarme en explicar cómo la inseguridad de género que experimentan los estudiantes adolescentes evidencia un terrible vacío en la importancia que las políticas públicas deberían tener con respecto a la construcción de entornos seguros con perspectiva de género, ya que el PES demuestra una falta de sensibilidad de género en el marco de proteger y enfatizar en las situaciones inequitativas hacia el interior de los contexto educativos. Cabe mencionar que las estudiantes reciben violencia de hombres y de mujeres, pero esta violencia tiene un marcado sesgo de género impuesto como elemento normativo de castigo y sanción; mujeres que ofenden a otras mujeres basándose en preceptos culturales de castidad y pureza con respecto a la sexualidad, la apariencia y "el buen comportamiento" hacen del carácter represor una constante forma de actuar. 
Algo que llamó mucho mi atención es el grado de insatisfacción y depresión que experimentan por lo menos 16 estudiantes mujeres de esta muestra etnográfica, ya que ellas presentan una violencia familiar basada en el descuido de los padres, la infravaloración y las constantes ofensas verbales, lo anterior, aunado a la escasa y pobre situación económica. Estos contextos de violencia y machismo hacen que dentro del espacio familiar las estudiantes absorban violencias que las mina en su integridad. En las entrevistas salía a relucir la preocupación y el estrés causado por una difícil situación en la casa, mientras tanto, el espacio comunitario también es altamente hostil para las mujeres, ya que existe un comportamiento reiterado de casos de violencia sexual, el cual se ha presentado como un fenómeno al que le han restado importancia las autoridades jurídicas y policíacas, mostrando o disimulando su importancia bajo explicaciones del tipo de trastorno de hombres machistas que ante la desprotección de las jóvenes las han atacado. Existen por lo menos 11 casos vinculados a ataques sexuales en los últimos dos años hacia jóvenes de esta comunidad, los cuales no salen a la luz pública pues quedan relegados a prácticas y conflictos entre parejas jóvenes prematrimoniales, donde los padres han decidido, en varios casos, casar a las mujeres con los hombres que las han atacado. Esto es muy grave, ya que por ejemplo para Luciana Ramos (2005), la posibilidad de violación sexual tiene fuertes efectos entre quienes la sufren directamente, y es generadora de temores y terrores. Esta autora explica que la inseguridad maximizada que experimentan las mujeres en su vida cotidiana aunada a la sistemática violencia provoca una instrumentación del miedo al grado de un "terrorismo sexual", donde nunca desaparece esa posibilidad de sentirse insegura.

Yo tengo miedo y mi madre tiene miedo también, ella me dice que no pase o que no salga de noche o cuando se pone obscuro, aquí sabemos que hay calles donde es muy peligroso caminar muy temprano o cuando se empieza a obscurecer porque ahí han pasado ataques a mujeres, mis amigas me dicen de cosas que pasan y la gente también lo dice... a mí me han dicho palabras ofensivas cuando salgo de la escuela casi enfrente de los mismos policías o incluso ellos se me quedan viendo de forma extraña o desconfiada que no me gusta (Entrevista a estudiante mujer de 13 años).

La comunidad es poco segura porque pasan muchas cosas y la escuela es segura pero no del

76 Seguridad de género en adolescentes escolares rurales. Un análisis del Programa Escuelas Seguras en México Julio U. Morales-López 
todo, hemos sabido de alumnos que meten droga y de hombres o muchachos que siguen a las estudiantes cuando salen y las van acompañando aunque ellas no quieran... hay compañeros que han castigados [sic] varias veces porque molestan a las compañeras y el maestro sí nos cree cuando denunciamos pero lo castigan y luego vuelve a hacer lo mismo. Hay una amiga a la que su primo se ha peleado dos veces por defenderla de un estudiante de la escuela, y al primo lo amenazaron de que lo iban a golpear o hasta matar porque con el muchacho con el que se peleó es amigo de otros que están en pandillas, y por eso ahora mi amiga tiene miedo de decirle a alguien si la molestan porque vayan a golpear o peor a matar a su primo (Entrevista a estudiante mujer de 15 años).

La pugna por el control de los cuerpos es una constante en sociedades e instituciones conflictivas, y en este sentido, acciones para dominar al género femenino son muestras de esto, sin embargo, los argumentos dados en las entrevistas arriba citadas nos exponen que la violencia ha escalado hasta atentar contra la integridad y la vida, así también, la inseguridad gestada en los intersticios del espacio comunitario y el espacio escolar ha permeado en estructurar el miedo como una constante, es decir, la violencia e inseguridad existen en general para todos los sujetos, pero en las mujeres recae con mayor grado, pues el riesgo aumenta y el miedo está presente en casi todos los ámbitos sociales. Las acciones de los estudiantes "problemáticos" deberían ser inocuas, no obstante, la incapacidad para detectar, administrar y transformar el conflicto por parte de las autoridades escolares ha creado que el conflicto derive en acciones violentas infligiendo dolor y angustia en las víctimas.

El concepto de inseguridad de género enfatiza también en aspectos de institucionalización de la inseguridad y los ecoentornos, es decir, los ámbitos en que las estructuras de poder y autoridad funcionan para normar el comportamiento dentro de los contextos.

En el marco de esta investigación se realizaron dos talleres sobre "violencias y otras masculinidades", donde la idea central era reflexionar en los ámbitos en que la masculinidad y sobre todo la virilidad están construidos sobre órdenes agresivos y autoritarios oprimiendo principalmente a las mujeres y después a otros hombres. Como resultado de los talleres se puede concluir que los estudiantes hombres han perfilado modelos de masculinidad basados en preceptos 
culturales violentos, que se han vuelto más peligrosos al incorporar estereotipos derivados de la migración y sobre todo del cercano roce de inseguridad y violencia que viven en sus regiones como: el narcotráfico, los secuestros y el robo, el ideal de éxito basado en el poder económico, la ostentación, el lenguaje peyorativo y machista de la música de narcocorridos, la familiaridad con las armas de fuego, etc.; lo destacable de los talleres realizados es que su percepción se mantiene casi intacta aun cuando los estudiantes están siendo educados y escolarizados de manera diaria.

Es decir, los tres años de educación secundaria les han servido para formarse en asignaturas científicas, del saber y conocimiento, pero no han hecho casi nada para transformar sus preceptos en cuanto a las relaciones y respeto entre los géneros, lo anterior evidencia la fundamental importancia de cómo está construida la escuela como institución de ciencia, conocimiento y saberes de tipo masculino, autoritario y poco sensitivo.

Los talleres de masculinidad subrayaron los códigos válidos para el pensamiento de la juventud, y la noción de que la violencia se combate con mayor violencia y ostentación de ella. La masculinidad en estos adolescentes es un modelo en construcción por cuotas de poder que muy posiblemente les acompañará toda su vida.

\section{Reflexiones finales}

El PES habla de un tipo de inseguridad que sí importa al Estado, aquella que es derivada de la falta de control militar, de gobernabilidad y reconocimiento social que está haciendo estragos en casi todos los sectores de la sociedad mexicana. Pero además de esta inseguridad, que es muy preocupante, existe otro tipo de inseguridad cotidiana, que es sistémica y es ejemplar, ya que permea en todos los estratos e instituciones de la sociedad, incentiva la violencia y los contextos inseguros y daña sensiblemente a la mitad de los estudiantes.

La inseguridad de género en contextos escolares es, como podría explicar Oswald, un recordatorio de que las mujeres desafían los lineamientos autoritarios androcéntricos al asistir a la escuela, al educarse las mujeres están luchando por salir de esa opresión de subvaloración de posiciones en la escala de lo sociocultural, lo político y lo económico. Por su parte, como expone Reardon existe una guerra sistémica que, dominada por un sinfín de contextos históricos y políticos, ha creado una realidad

78 Seguridad de género en adolescentes escolares rurales. Un análisis del Programa Escuelas Seguras en México Julio U. Morales-López 
compleja de inseguridad y violencia, que ha optado por atender y dar ayuda de una forma inequitativa.

En ese sentido, el PES es una reiteración de una política pública patriarcal más, que defiende determinados intereses en aras de un modelo ya consolidado y que en su propia constitución reproduce el conflicto, no se trata de dejar fuera lo fundamental que resulta proteger a los estudiantes en contextos de inseguridad derivados de la "guerra contra el narco", sino más bien, que los grandes acontecimientos históricos -como las guerras militares, políticas, ideológicas, etc.- deberían dar pauta para soluciones integrales y prospectivas que perfilen una transformación más allá de solo paliativos sesgados.

\section{Referencias bibliográficas}

Bauman, A. (2000). Modernidad líquida. Buenos Aires, Argentina: Fondo de Cultura Económica (FCE).

Centro Tepoztlán AC. (2010). La inseguridad humana y otras seguridades e inseguridades. Reunión-Diálogo. Disponible en: http://codexvirtual. com/bmlt3/wp-content/uploads/ponencias/20100417.pdf

Mack, A. (2005). El concepto de seguridad humana. Papeles de cuestiones internacionales (90), 11-18.

Massolo, A. (2005). Género y seguridad ciudadana: el papel y reto de los gobiernos locales. Seminario Permanente sobre violencia. Estudios Centroamericanos ECA. San Salvador.

Organización de las Naciones Unidas. (2000). Nosotros los pueblos: la función de las Naciones Unidas en el siglo XXI. Informe del Secretario General, quincuagésimo cuarto periodo de sesiones, Tema $49 \mathrm{~b}$ del programa. Asamblea de las Naciones Unidas dedicadas al Milenio. Disponible en: http://unpan1. un.org/intradoc/groups/public/documents/un/unpan004567.pdf

Oswald, U. (2013). Seguridad de Género. Flores, F. (Coord.), Representaciones sociales y contextos de investigación con perspectiva de género. México: CRIM-UNAM.

Ramos, L. (2005). Miedo a la violación e inseguridad en las mujeres. López, C., Francisco, U. y Vázquez, J. (Coords.). Globalización, violencia y derechos humanos: Entre lo manifiesto y lo oculto. México: UAMI- Editorial Ítaca.

Ramos, V. (2012). La libertad y seguridad. La antropología de Thomas Hobbes. Revista Jurídica Jalisciense. (47), 15-39.

Reardon, B. (1996). Sexismo y el sistema guerra. USA: University Press Edition, Columbia University.

Recasens, A. (2005). Aproximaciones antropológicas al fenómeno de la violencia. Revista de Antropología (18), 31-58.

Secretaría de Gobernación. (2008). Bases de Operación para el Programa Escuela Segura. Disponible en: http://basica. sep.gob.mx/escuelasegura/pdf/transparencia/basesPES.pdf 
Subsecretaría de Educación Básica (SEB). (Sin fecha). Programa Nacional de Escuela Segura. Disponible en: http://basica.sep.gob.mx/escuelasegura/start.php
Zeitlin, J. y Mpoumou, D. (2004). No hay seguridad humana sin igualdad de género. Women's Environment Eु development organization (WEDO). Disponible en: www.catedradh.unesco.unam. $\mathrm{mx} /$ SeminarioCETis/Documentos.pdf www.wedo.org/5050kit.htm 